\title{
Correction: Association of ACE2 genetic polymorphisms with hypertension-related target organ damages in south Xinjiang
}

\author{
Yi Luo ${ }^{1} \cdot$ Cheng Liu ${ }^{1,2,3} \cdot$ Tianwang Guan ${ }^{2} \cdot$ Yanfang $\mathrm{Li}^{2} \cdot$ Yanxian Lai ${ }^{1} \cdot$ Fang Li $^{3} \cdot$ Haiyan Zhao ${ }^{3} \cdot$ Tutiguli Maimaiti $^{3}$. \\ Abudurexiti Zeyaweiding ${ }^{3}$
}

Published online: 23 January 2019

(C) The Japanese Society of Hypertension 2019

\section{Correction to: Hypertens Res}

https://www.nature.com/articles/s41440-018-0166-6 published online 12 December 2018
The version of this article originally published was not open access. This article should have been open access. The error has been fixed, and the article is now open access.

Cheng Liu

eyliucheng@scut.edu.cn

1 Department of Cardiology, Guangzhou First People's Hospital, Medical School, South China University of Technology, 510180 Guangzhou, China

2 Department of Cardiology, Guangzhou First People's Hospital, Guangzhou Medical University, 510180 Guangzhou, China

3 Department of Cardiology, Shufu People's Hospital, Xinjiang Uygur Autonomous Region (XUAR), 844100 Kashgar Region, China 